\title{
The Construction of Medical Multimedia Database
}

\author{
Na Wang ${ }^{1,}$, Corresponding author: Jinguo Wang ${ }^{2, b}$ \\ ${ }^{1}$ Department of Anesthesiology, The First Hospital of Jilin University, Changchun, 130021, China \\ 2Department of Urology, The First Hospital of Jilin University, Changchun, 130021, China \\ aemail: wangna080613@163.com, bemail: wangjinguolily@163.com
}

Keywords: Medicine; Construction; Multimedia; Database

\begin{abstract}
Construction of medical multimedia database is beneficial to realize remote medical education and improve the efficiency of multimedia resources. The construction of the medical multimedia database not only needs modern information technology and network platform, but also needs to carry on the integration of all resources.
\end{abstract}

\section{Introduction}

Modern technology development along with information society is more and more changing our mode of production, life, work and learning. It is necessary to make and implement remote education in the development of information technology in our country, in planning and how to do the most cost-effective, pay attention to the study and draw lessons from the beneficial experience of abroad, and on the hardware infrastructure such as computer configuration at the same time, to pay special attention to use these techniques of teachers training. Information acquisition, analysis, processing and application ability will be as a symbol of modern people's most basic ability quality, and enhance the comprehensive national strength is an important part [1].

Collect resources, and then integrate them together in the form of a network platform of multimedia resource. In order to provide systematic teaching content, provide the course catalog and chapter for resource using [2]. In order to solve the teaching process of multimedia resources scattered, lack of clear, practical problems such as resources and teaching needs decoupling, relying on the existing network resources, the use of multimedia technology, computer technology, network technology and other means to build multimedia information repository.

\section{The advantages of multimedia database}

The implementation of teaching resources is sharing. Teachers collect information and make a good upload database backup, provide convenience for other teachers teaching, teaching resources sharing. It provides rich multimedia resources. Teachers in the client can choose freely and collect in the repository map, text, sound, like the media material, prepares a lesson to optimize teaching design, improve efficiency, reduce the pressure of job of teaching.

Learners can really benefit from convenience got by multimedia information. It takes advantage of the ubiquitous mobile communication technologies. Medical students should possess summary data and solve problem. In the teaching, should require everyone to write a written report. It is designed to motivate students' interest in learning. Training literature search and writing ability, raises the student good self-study habits, literature search and review the textbook knowledge is no longer boring. It can help students to increase their thinking ability and the consciousness of self knowledge update [3].

\section{Difficulties which may be encountered}

Because of medical specialty is a very professional, the network teaching resource database construction involves a lot of problems, applied also to have certain difficulty, so reform of higher medical colleges and universities teaching technology has always been a big problem. So in this 
context research medical network teaching resource construction is of great realistic significance and practical value. This paper gave the concept, characteristics, basic composition, the construction principle and the change mode of medical network teaching resource, on the basis of the questionnaire survey according to the current status of medical network teaching resource database application in our country which introduces the construction of teaching resource database and application of the final result [4].

The analysis shows that the establishment of teaching resource database is helpful for learners to grasp of the medical knowledge, to increase learning enthusiasm and interest significantly. In order to promote autonomous learning and meet the needs of the education, good teaching modes have adapted to the practical need. The growing of network teaching resources needs to improve construction and utilization of database. It is hoped that through this article research can promote medical network in colleges and universities teaching resource database construction and reasonable application of science to provide some useful reference and reference.

This research mainly adopts the following method. Literature review method, through to the related teaching resource database construction and medical research literature for the construction of network teaching resource database read, summarized and put forward my own point of view. Data analysis, network teaching resource database construction of the relevant data, case, analyzing the problem of medical network teaching resource database construction in our country and the reasons, and in combination with these problems, put forward the corresponding solutions.

\section{The concept and advantages of multimedia teaching resource}

Network technology makes the limited teaching time to achieve the teaching of the new, enhanced the students of the breadth and depth of knowledge, cultivate the students' ability of analyzing and processing information, especially the highly innovative ability makes it become the creative talent. Rather than accept only teachers imparting knowledge, only will recite the previous books. Knowledge workers are not good at innovation [5]. So how many years is bound to fundamentally change the relationship between teaching and learning of teachers and students in the interactive teaching and learning will be in the first place. Instead of teachers on the relationship between the students' knowledge of one-way transfer information any individual is with a personal project.

Mobile communication tool is one of the typical carriers. Under the guidance of this concept, the micro learning strategy is a practical short block to design the content of the learning content, appears in the media of micro miniature course content. In a variety of mobile communication tools to carry the micro content, and design in the content, the interactive communication is between learners. The feasibility of mobile learning is guaranteed by informal learning theory. Learning has both individuality characteristic, also has social features. Based on individual learning activities such as reading and thinking knowledge gained by the profound and with a certain bias, but spend more time and requires perseverance [6].

According to the characteristics of the internet study, in addition to academic studies, most people tend to get information through lectures, discussions and social learning activities. Internet learning is a kind of non steady learning and attention is highly fragmented at anytime and anywhere. The external environment is very important for learning cognition. Design of mobile learning curriculum is the key to the content of the micro organization.

\section{How to establish medical teaching multimedia database}

First, in the hardware design, a concrete quality standard should be given to facilitate the subsequent acquisition and processing of data. Second, in the software, the system should automatically identify repeated resources, and get rid of them [7]. Finally, senior administrator should be identified for checking the resources to distinguish the resources with good quality. Repository storage space is limited, in order to reasonable use of resources, should set up a quality control module. 
Data collection is an important part in the construction of teaching resource, should make full use of Internet resources, search and select suitable material, and in their place after by editing processing. Learning in medical school or research institutions is also a method of collection of teaching resources. In daily teaching process, the different teaching object oriented teaching plans, such as ware, teaching material should be paid attention to collection and preservation [8]. To print data can be digitized by scanning, using image processing software and character recognition software to deal with the processing, to obtain information to meet the teaching needs. It can use a digital camera and a camera for video class data access directly, can also be used by purchasing the audio and video products on the market access, using video editing software, capture the part of the need for use.

At the beginning of the teaching resource construction, all resources can be collected on a computer, designated special maintenance personnel to handle classification, and unified the upload, according to the course catalog in chapter order entry related teaching resources. At the same time, according to the knowledge in the curriculum standard extract chapters as subsequent database development of join points. Repository set up for after the completion of each teacher assigned user name and password, the teacher according to the updating resources need to be independent and download, more repository site real-time services [9]. Finally, the repository administrator should be conducted on a regular basis the repository for inspection and maintenance.

\section{Conclusion}

Multimedia teaching resource construction is the foundation of modern network distance medical education of engineering, multimedia database based on network can more reasonably and more effectively for teaching material and information, is conducive to improve the efficiency of teachers' lessons and the course manufacture level. In the process of construction and use, some problems need to pay attention. In the process of resource acquisition, it comes to copyright issues, should indicate the source in prominent locations, and the author. A stable and large capacity of the corresponding hardware and campus network system is very important for construction and application of multimedia database and flexible guarantee of the information data. The construction of multimedia database is a system engineering, must according to the development of the discipline, in a timely manner resource adjustment and supplement of chosen for subsequent construction and maintenance.

In the age of information processing ability is an indispensable important part of teachers' quality. However, compared to the same some polytechnic colleges, current and other medical colleges and universities are generally exists in our school teachers of the computer is not able to skilled application of information technology. Even engaged in computer teaching of teacher, on the quantity and quality can not meet the demand of the rapid development of information technology, thus on teachers in general, there are information technology to learn, to improve such an urgent and important problem. Each teacher will face information quality requirements, is the selection, only set up the idea of lifelong learning to form a kind of learning.

\section{References}

[1] JJ. Norcini, DW. Mckinley. Assessment methods in medical education. Teaching and Teacher Education. 2007

[2] Wilkinson GL. Consolidated listing of evaluation creteria and quality indicators. http://iteth.lcoeuga edu/fault-y/gwilkinson/webeval.htm . 2009

[3] Introducing Librarians’ Internet Index. http: // www. itc.nl /Pub /Home / library /Library -general -information /more-info-databases /lii_info.html . 2009

[4] SOSIG: Social Science Information Gateway. http://www.ariadne.ac.uk/ issue2/sosig/. 2009

[5] Wilkinson GL, Bennett LT, Oliver KM. Evaluating critrtia and indicators of quality for internet 
resources. Educational Technology. 1997

[6] Keeney S, Hasson F, McKenna HP.A critical review of the Delphi technique as a research methodology for nursing. International Journal of Nursing Studies. 2001

[7] John Sitzia.Howvalid and reliable are patient satisfaction data? An analysis of 195 Studies. International Journal for Quality HealthCare. 1999

[8] Moussa A, Bridges-Webb C. Quality of care in general practice: a delphi study of indicators and methods. Australian Family Physician. 1994

[9] Gallagher M, Bradshaw C, Nattress H. Policy priorities in diabetes care: a Delphi study. Quality in Health Care. 1996 